\title{
Cyclosporine A nephrotoxicity: Downregulation of multidrug resistance associated protein 2 (MRP2) by upregulated miRNA133a
}

\author{
Jochen WU Fries ${ }^{1,2 *}$, Joe Schankin ${ }^{1}$, Sandra Stefanikova ${ }^{1}$, Melanie von Brandenstein ${ }^{2}$, Reinhard Büttner ${ }^{1}$ and Heike Goebel ${ }^{1}$ \\ ${ }^{1}$ Department of Pathology, University Hospital of Cologne, Cologne, Germany \\ ${ }^{2}$ Department of Urology, University Hospital of Cologne, Cologne, Germany
}

\begin{abstract}
Background: Multidrug resistance associated protein 2 (MRP2) is described as a transport protein for xenobiotics, such as cyclosporine A (CyA). We have shown in proteinuric diseases that miRNA133a downregulates MRP2 by binding to its 3'UTR region, inducible by endothelin-1 (ET-1) via the ETB-receptor. The mechanism of nephrotoxicity in CyA treatment is still elusive. In particular, co-morbidities/clinical parameters, the morphological extent of MRP2 damage and the involvement of miRNA133a as a potential mechanism leading to nephrotoxicity have not been investigated.
\end{abstract}

Aims: To analyze co-morbidities, and the role of ET-1 and miRNA133a in CyA renal toxicity.

Methods: The effect of ET-1 alone or in combination with CyA on MRP2 and miRNA133a levels was studied in human proximal tubular cell culture. Comorbidities/clinical factors in 230 biopsies from 124 patients were analyzed. Immune histology and morphometry of MRP2 expression was performed in 36 CyA biopsies (tubular damage, arteriolar damage, no damage) and in controls ( 5 null biopsies, 5 probes of normal renal tissue from benign tumor resection). On those specimens, a qRT-PCR for the detection of mrp2 and miRNA133a levels was also investigated.

Results: No single clinical parameter was statistically found responsible for CyA nephrotoxicity. Morphometric analysis revealed an increasing degree of MRP2 loss, i.e., no CyA toxicity to arteriolar / combined arteriolar, and tubular toxicity which showed the maximum degree of damage. In human proximal tubular cell culture, the combination of ET-1 and CyA had a higher effect of MRP2 loss/miRNA133a upregulation than ET-1 alone. By qRT-PCR, CyA induced marked tubular damage by downregulating the mrp2 gene via the upregulation of miRNA133a. However, transcriptional levels for mrp2 in arteriolar damage were high.

Conclusion: Downregulation of MRP2 by miRNA133a is an important mechanism of CyA tubular nephrotoxicity. Urinary analysis as detection assay and treatment options by an ETB-receptor antagonist are discussed.

\section{Introduction}

Endothelin-1 (ET-1), a major mediator of cellular signaling in human renal proximal tubule cells [1,2], is associated with regulation of multidrug resistance associated proteins (MRPs 1-6) [3]. Their function of increased drug efflux causes the multiple drug resistant phenotype [4,5]. If disturbed, it leads to nephrotoxicity [6,7]. ET- 1 acting via ETB- receptor (ETBR) but not via ETA-receptor (ETAR) is able to downregulate MRP2 [3,8].

MicroRNAs (miRNAs), short, non-coding RNAs, play important roles in cell function and development. Loeser, et al. described in human proteinuric disease that ET-1 stimulation via ETBR results in an upregulation of miRNA133a. This miRNA downregulates the mrp2 gene by interacting with its 3'UTR, causing loss of MRP2 protein expression at the tubularsurface.

Xenobiotics such as Cyclosporine A (CyA) are transported by MRP2 [9], whichisnormally presenton theluminalsurfaceof proximal tubules [7]. CyA activates ET-1 in the kidney [10] in renal proximal tubules [11,12] and upregulates ETBR [13]. Since CyA induces different types of nephrotoxicity (i.e., arteriolar, tubular, arteriolar and tubular), weinvestigated the effect of ET-1 vsET-1+CyA in cell culture, a morphometric analysis of immune histologic detection of MRP2 in biopsies with different types of CyA nephrotoxicity, and the levels of MRP2 and miRNA133a by qRT-PCR in those biopsies. We show that MRP2 loss is correlated with miRNA133a upregulation in tubular damage. Since urinary detection of miRNA133a is possible, a clinical study using urine analysis of this miRNA and treating patients with an ETB-receptor antagonist could be valuable to better control tubular CyA toxicity.

\section{Materials and methods}

\section{Approval for the procurement of human material}

Since human tissue was investigated, procedures were followed as outlined in accordance with ethical standards, formulated in the Helsinki Declaration 1975 (and revised in 1983), or the Declaration of Istanbul (for transplant biopsies) with pre-approval by the Ethics Committee at the University Hospital, Cologne (Cologne, Germany; reference number: 19-350; tumor tissue through Biomasota protocol).

*Correspondence to: Jochen WU Fries, Department of Pathology, University Hospital of Cologne, Cologne, Germany, Tel:492214786061;Fax:492214786360; E-mail: jochen.fries@uni-koeln.de

Key words: cyclosporine nephrotoxicity, endothelin-1, miRNA133a, multidrug resistance associated protein 2

Received: May 05, 2020; Accepted: May 20, 2020; Published: May 23, 2020 


\section{Human tissues}

Formalin-fixed and paraffinized human renal biopsies were selected from the archives of the Department of Pathology, University Hospital of Cologne, Germany. Histologic evaluation was based on independent analyses by two staff pathologists(HGand JWUF) using HematoxilinEosinstained, paraffin-sections. The following sets of cases were used:

1. Human renal proximal tubule cell culture: Primary human renal proximal epithelial tubules cells (RPTECs) were purchased from Cambrex (CC-2553; CambrexBio Science). These were cultured according to the manufacturer's instructions using renal epithelial cell base medium (without growth factors, CC-3191) plus renal epithelial cell medium SingleQuots (CC-4127) at $37^{\circ} \mathrm{C}$ and $5 \% \mathrm{CO}_{2}$. Passage 6-7 cells were used. For all experiments, cells were pre-incubated for $24 \mathrm{~h}$ with serum-free renal epithelial cell medium.

2. Human biopsies with Cyclosporin A toxicity: A bioptical classification according to BANFF 2007 was performed. A total of 230 biopsies from 124 patients over a period of four years (20082011; Department of Pathology, University Hospital of Cologne) were rescreened, of which 107 were studied further (Table 1). Per case, four periodic acid Schiff (PAS) stained sections were obtained with 1-2 sections each, of which the arterioles and tubules in five randomized fields were counted. Cross-sectioned tubules were preevaluated using vacuolization of all epithelial cells in each facial field, and the damage sub classified (i.e., no vacuolization: 0 ; one to four tubules with vacuolization: 1 ; four to ten tubules with vacuolization: 2 ; and more than 10 tubules with vacuolization: 3 ). The arteriolar damage is characterized by a hyalinosis, which is subdivided into subendothelial, transmural, and circular categories. The transmural and the circular damage is caused by CyA, and was classified following BANFF 2007 classification (aah: arteriolar hyaline thickening, aah0: no typical lesions of CNI arteriolopathy; aah1: replacement of degenerated smooth muscle cells by hyaline deposits present in only one arteriole, no circumferential involvement; aah2: replacement of degenerated smooth muscle cells by hyaline deposits present in more than one arteriole, but no circumferential involvement; aah3: replacement of degenerated smooth muscle cells by hyaline deposits with circumferential involvement, independent of the number of arterioles involved [14].

3. Control renal tissue as reference: Renal biopsies were taken from the renal transplant (so-called null biopsies; $n=5$ ) but with subsequent failure of allocation (Table 2). Five specimens from normal renal tissue resected in the context of a benign tumor (Oncocytoma) were also used as additional controls for ischemic damage (Table 3 ).

Table 1. Patients' biopsies after kidney transplantation treated with Cyclosporine A used for miRNA and MRP2 analysis

\begin{tabular}{|c|c|c|c|c|c|c|c|c|}
\hline No. & Ref. No. & Age & $\begin{array}{c}\text { Time after } \\
\text { TX }\end{array}$ & Gender & Creatinine mg/dl & $\begin{array}{c}\text { Prot. } \\
\text { g/d }\end{array}$ & Reject. & Damage \\
\hline $11 \#$ & 22 & 46 & 1.089 & $\mathrm{~m}$ & & & yes & no \\
\hline $16 \#$ & 29 & 34 & 62 & $\mathrm{~m}$ & $3.4-4 \mathrm{mg} / \mathrm{dl}$ & & no & no \\
\hline $18 \#$ & 37 & 67 & 6.900 & $\mathrm{~m}$ & $1.3 \mathrm{mg} / \mathrm{dl}$ & & yes & no \\
\hline $20 \#$ & 39 & 57 & 4.680 & $\mathrm{f}$ & increasing & & yes & no \\
\hline $22 \#$ & 41 & 60 & 60 & $\mathrm{f}$ & & & no & no \\
\hline $26 \#$ & 47 & 23 & 30 & $\mathrm{~m}$ & $3.5 \mathrm{mg} / \mathrm{dl}$ & $96 \mathrm{mg} / \mathrm{g}$ & no & no \\
\hline $49 \#$ & 101 & 52 & 2.520 & $\mathrm{~m}$ & $5 \mathrm{mg} / \mathrm{dl}$ & & no & no \\
\hline $50 \#$ & 102 & 66 & 14 & $\mathrm{~m}$ & $4.8 \mathrm{mg} / \mathrm{dl}$ & & no & no \\
\hline $51 \#$ & 103 & 45 & 10 & $\mathrm{f}$ & $10 \mathrm{mg} / \mathrm{dl}$ & & yes & no \\
\hline $55 \#$ & 109 & 38 & 9.999 & $\mathrm{f}$ & $3.4 \mathrm{mg} / \mathrm{dl}$ & & no & no \\
\hline $58 \#$ & 116 & 19 & 60 & $\mathrm{~m}$ & & & yes & no \\
\hline $59 \#$ & 122 & 21 & 30 & $\mathrm{~m}$ & $3 \mathrm{mg} / \mathrm{dl}$ & & yes & no \\
\hline $61 \#$ & 2 & 72 & 9.999 & $\mathrm{f}$ & $11.4 \mathrm{mg} / \mathrm{dl}$ & & no & tubular \\
\hline $64 \#$ & 33 & 46 & 360 & $\mathrm{f}$ & increase & & yes & tubular \\
\hline $65 \#$ & 34 & 70 & 360 & $\mathrm{f}$ & $3.4-4 \mathrm{mg} / \mathrm{dl}$ & & no & tubular \\
\hline $67 \#$ & 36 & 73 & 360 & $\mathrm{~m}$ & $6 \mathrm{mg} / \mathrm{dl}$ & & yes & tubular \\
\hline $68 \#$ & 45 & 10 & 14 & $\mathrm{~m}$ & no function & & no & tubular \\
\hline $72 \#$ & 66 & 20 & 24 & $\mathrm{f}$ & $6.2 \mathrm{mg} / \mathrm{dl}$ & & no & tubular \\
\hline 72\# & 66 & 20 & 24 & $\mathrm{f}$ & $7.5 \mathrm{mg} / \mathrm{dl}$ & & no & tubular \\
\hline $76 \#$ & 83 & 52 & 30 & $\mathrm{~m}$ & $3.6 \mathrm{mg} / \mathrm{dl}$ & & no & tubular \\
\hline $78 \#$ & 87 & 15 & 90 & $\mathrm{f}$ & & & no & tubular \\
\hline 79\# & 90 & 41 & 10 & $\mathrm{f}$ & & & yes & tubular \\
\hline $81 \#$ & 105 & 69 & 20 & $\mathrm{~m}$ & $2.9 \mathrm{mg} / \mathrm{dl}$ & & yes & tubular \\
\hline $84 \#$ & 115 & 59 & 3.600 & $\mathrm{f}$ & & & no & tubular \\
\hline $86 \#$ & 120 & 73 & 15 & $\mathrm{f}$ & & & no & tubular \\
\hline $89 \#$ & 16 & 51 & 905 & $\mathrm{~m}$ & & & no & arteriolar \\
\hline $91 \#$ & 20 & 79 & 2.896 & $\mathrm{f}$ & $4.5 \mathrm{mg} / \mathrm{dl}$ & & no & arteriolar \\
\hline 93\# & 49 & 34 & 9.999 & $\mathrm{~m}$ & $1.0->1.5 \mathrm{mg} / \mathrm{dl}$ & & no & arteriolar \\
\hline $94 \#$ & 50 & 62 & 9.999 & $\mathrm{f}$ & & & no & arteriolar \\
\hline $95 \#$ & 53 & 72 & 60 & $\mathrm{~m}$ & & & no & arteriolar \\
\hline $96 \#$ & 55 & 73 & 3 & $\mathrm{~m}$ & $2.5->3.5 \mathrm{mg} / \mathrm{dl}$ & $3.9 \mathrm{~g} / \mathrm{g}$ & no & arteriolar \\
\hline $100 \#$ & 76 & 70 & 9.999 & $\mathrm{~m}$ & $4.1 \mathrm{mg} / \mathrm{dl}$ & $386 \mathrm{mg} / \mathrm{g}$ & no & arteriolar \\
\hline $102 \#$ & 91 & 67 & 9.999 & $\mathrm{~m}$ & $3.2 \mathrm{mg} / \mathrm{dl}$ & & yes & arteriolar \\
\hline $105 \#$ & 98 & 49 & 14 & $\mathrm{~m}$ & & & yes & arteriolar \\
\hline $107 \#$ & 117 & 62 & 9.999 & $\mathrm{~m}$ & $6 \mathrm{mg} / \mathrm{dl}$ & & no & arteriolar \\
\hline
\end{tabular}

Note: Prot: Proteinuria; TX: Transplantation; Reject: Rejection 


\section{Cell culture analysis of MRP2 and miRNA133a}

RPTECs were grown to 80-90\% confluence and treated with ET-1 (50 nM, Sigma, E7764), or ET-1 plus Cyclosporine A (Sandoz Pharmaceutical; $200 \mathrm{ng} / \mathrm{mL}$ ) for 72 hours, washed with phosphatebuffered saline (PBS), and prepared for qRT-PCR/Western blotting. All treatment studies were done in triplicate. As controls, RPTECs were grown without fetal calf serum for $24 \mathrm{~h}$.

\section{Evaluation of human transplant biopsies after Cyclosporine A treatment}

Fromhuman transplantbiopsies afterCyA treatment, all available clinical information was collected in the following three categories: clinical parameters, laboratory values, and medications (Table 4).

\section{Immune histology for MRP2}

From formalin-fixed, paraffinized archival tissue blocks of renal biopsies, $4 \mu \mathrm{m}$ thick sections were cut, mounted on glass slides, and dried for $45 \mathrm{~min}$. at $60^{\circ} \mathrm{C}$. Fordeparaffinization, slides weresubmersed

Table 2. Control renal biopsies at time of transplantation (no allocation)

\begin{tabular}{|c|c|c|c|}
\hline Patient ID & Diagnosis & Age (years) & Gender \\
\hline 1 & Null bx; Tx & 24 & $\mathrm{f}$ \\
\hline 2 & Null bx; Tx & 28 & $\mathrm{f}$ \\
\hline 3 & Null bx; Tx & 30 & $\mathrm{~m}$ \\
\hline 4 & Null bx; Tx & 29 & $\mathrm{~m}$ \\
\hline 5 & Null bx; Tx & 64 & $\mathrm{~m}$ \\
\hline
\end{tabular}

Table 3. Control renal tissue from tumor resection specimens (Oncocytoma)

\begin{tabular}{|c|l|c|c|}
\hline Patient ID & Diagnosis & Age (years) & Gender \\
\hline 1 & Normal kidney; tumor resection & 48 & $\mathrm{f}$ \\
\hline 2 & Normal kidney; tumor resection & 67 & $\mathrm{f}$ \\
\hline 3 & Normal kidney; tumor resection & 49 & $\mathrm{~m}$ \\
\hline 4 & Normal kidney; tumor resection & 59 & $\mathrm{~m}$ \\
\hline 5 & Normal kidney; tumor resection & 61 & $\mathrm{~m}$ \\
\hline
\end{tabular}

Table 4. Human transplant biopsies evaluated using the following three categories: clinical parameters, laboratory values, and medications

\begin{tabular}{|l|l|l|}
\hline Clinical Parameter & Lab Values & Medications \\
\hline Age of patient & Hypercholesterinemia & ACE-inhibitors \\
\hline Age of transplant & Creatinine & Calcium-antagonist \\
\hline Gender & Protein in urine & Diuretic \\
\hline Ntx Rejection & Glucose in urine & Beta-blocker \\
\hline Damage by Cya toxicity & Total protein & Thyroxin \\
\hline Grading of damage & Urea & PTH \\
\hline Body size & LDH & Antibiotics \\
\hline Body weight & yGT & Bisphosphonate \\
\hline Blood pressure & GOT & Immunosuppressive drugs \\
\hline Diabetes mellitus & GPT & \\
\hline Adipositas & Hemoglobin & \\
\hline & Erythrocyte no. & \\
\hline & MCHC & \\
\hline & $\begin{array}{l}\text { Erythrocyte sedimentation } \\
\text { speed }\end{array}$ & \\
\hline & Hbalc & \\
\hline & CRP & \\
\hline & Cyclosporine A levels & \\
\hline & Tacrolimus levels & \\
\hline & Sirolimus levels & \\
\hline & Y & \\
\hline & & \\
\hline & & \\
\hline & & \\
\hline & & \\
\hline
\end{tabular}

LDH: Lactate dehydrogenase; Ygt: y glutamyl-transferase; GOT: Glutamic oxaloacetate transaminase; GPT: Glutamic pyruvate transaminase; MCHC: Mean corpuscular hemoglobin concentration; CRP: C-reactive protein in Xylol and subsequently washed for 3 min each at room temperature (RT) in alcohol baths with decreasing concentration. Antigen retrieval was achieved by exposing the section at $100^{\circ} \mathrm{C}$ in a $0.01 \mathrm{M}$ sodium citrate buffer ( $\mathrm{pH}$ ) for $20 \mathrm{~min}$. After cooling to RT for $20 \mathrm{~min}$ in this buffer, sections were washed twice, and endogenous peroxidase was blocked using 3\% hydrogen peroxide for $30 \mathrm{~min}$. After a subsequent BSA block for $2 \mathrm{hrs}$ at RT, sections were incubated overnight at $4^{\circ} \mathrm{C}$ with the primary antibody against MRP2 (ABIN445913) diluted to 1:200. After washing twice, the secondary antibody labeled with Diaminobenzidine was applied for two hours at RT using a Thermo Autostainer. The enzyme reaction was carried out adding chromogen for $10 \mathrm{~min}$ at RT, after which the sections were dehydrated using ascending alcohol concentrations and cover-slipped for inspections.

\section{Morphometry of MRP2}

After PAS evaluation, from all CyA pretreated cases the ones with at least 60 well preserved tubular cross-sections were selected, resulting in cases with CyA damage of the arteriolar $(n=10)$, tubular type $(n=13)$, combined arteriolar + tubular type damage $(n=5)$, and 12 cases without identifiable CyA damage(Table 1). These were compared to 5 cases of normal renal tissue taken fromexplanted, butnot transplanted donor kidneys (no allocation in time) (Table 2) as well as 5 cases of normal renal tissue resected in the course of a benign renal tumor (Oncocytoma; Table3). Inallcases, tubuleswere classified according to four groups of MRP2 preservation (i.e., no MRP2 loss: $100 \%$; less than $50 \%$ MRP2 loss: $<50 \%$; more than $50 \%$ MRP2 loss: $>50 \%$; complete MRP2 loss: $0 \%$ ), and evaluated by ANOVA.

\section{Mrp2 gene and microRNA 133a analyses}

Renal biopsy cases from each of the afore mentioned groups (no CyA damage, arteriolar damage, tubular damage, so-called null biopsies; Table 1, all marked with \#), and from the 10 control cases (i.e., five cases of so-called null biopsies, Table5; five cases of normal renal tissue from tumor resection) were used for mRNA and microRNA analysis.

\section{Western blot analysis}

Nuclear extracts were isolated from endothelin treated and untreated RPTECs according to the manufacturer's protocol (Nuclear extraction kit, Active motif) [15]. Protein content was assayed with the Bradford protein assay (Bio-Rad) with BSA as standard. Proteins $(20 \mu \mathrm{g})$ were separated by $10 \%$ SDS-PAGE and transferred to a PVDF membrane (Carl Roth, Cat. No. T830.1). Membranes were incubated with specific antibodies against MRP-2 (Abcam, M2III-6; 1:500 in TBST for $16 \mathrm{hrs}$ at $4^{\circ} \mathrm{C}$ ), and $\mathrm{B}$-actin (Santa Cruz, sc-1616) followed by HRP-labeled secondary antibodies in conditions according to the manufacture's instructions. The bands were visualized using enhanced chemiluminescence Plus reagents (Pierce, ECL, 32109) according to the manufacturer's instructions and the highly sensitive Chemiluminescence-Diana III CCD (Bio Imaging) program.

\section{Densitometry}

For densitometrical analysis the LabImage 1D 2006 program was used according to the provided protocols [16]. Statistics: mean and standard deviation were calculated. Differences between matched groups were analyzed by $\mathrm{t}$-test for paired variables. Values of $\mathrm{p}<0.05$ were considered statistically significant $\left({ }^{*} p<0.05,{ }^{* *} p<0.01\right)$.

\section{miRNA isolation from FFPE samples/ cell culture}

For miRNA isolation of the FFPE samples, the miRNeasy FFPE kit from Qiagen was employed according to the manufacturer's 
Table 5. Result of evaluation of parameters from table 4

\begin{tabular}{|c|c|c|c|c|c|c|c|}
\hline & & \multicolumn{6}{|c|}{ Damage observed } \\
\hline & & \multicolumn{3}{|c|}{ NO } & \multicolumn{3}{|c|}{ YES } \\
\hline & & mean & $+/-$ STD & No. & mean & +/- STD & No. \\
\hline \multicolumn{2}{|l|}{ Age } & 49 & 16 & & 55 & 16 & \\
\hline \multicolumn{2}{|l|}{ time period of NTx } & 808 & 1794 & & 869 & 1589 & \\
\hline \multirow{2}{*}{ Gender } & female & & & 16 & & & 22 \\
\hline & male & & & 44 & & & 42 \\
\hline \multirow{2}{*}{ tx rejection } & No & & & 37 & & & 45 \\
\hline & Yes & & & 23 & & & 19 \\
\hline \multirow{4}{*}{ type of damage } & No damage & & & 60 & & & 0 \\
\hline & arteriolar damage & & & 0 & & & 22 \\
\hline & tubular damage & & & 0 & & & 27 \\
\hline & Combined damage & & & 0 & & & 15 \\
\hline \multicolumn{2}{|l|}{$\mathrm{BL}(\mathrm{cm})$} & 175 & 9 & & 171 & 10 & \\
\hline \multicolumn{2}{|l|}{ BW (kg) } & 81 & 15 & & 75 & 14 & \\
\hline \multicolumn{2}{|l|}{ RRSys } & 134 & 22 & & 129 & 23 & \\
\hline \multicolumn{2}{|l|}{$\mathrm{RR}(\mathrm{mmHg})$} & 77 & 14 & & 75 & 16 & \\
\hline \multicolumn{2}{|l|}{ RR (no medicine; sys) } & 139 & 26 & & 136 & 25 & \\
\hline \multicolumn{2}{|l|}{ RR (treated) } & 82 & 15 & & 79 & 17 & \\
\hline \multirow{2}{*}{ Diabetes } & no & & & 50 & & & 52 \\
\hline & yes & & & 10 & & & 12 \\
\hline Adipositas & no & & & 54 & & & 57 \\
\hline$(\mathrm{BMI}>30)$ & yes & & & 6 & & & 7 \\
\hline Hypercholes- & no & & & 46 & & & 49 \\
\hline $\begin{array}{l}\text { terinemia }(>200 \mathrm{mg} / \\
\text { dl) }\end{array}$ & yes & & & 14 & & & 15 \\
\hline Creatinine $(0.5-1.1 \mathrm{~m}$ & & 2.25 & 1.57 & & 2.57 & 2.03 & \\
\hline Gluces in urine & negative & & & 25 & & & 30 \\
\hline Glucose in urine & positive & & & 3 & & & 3 \\
\hline Frythrocytes in urine & negative & & & 14 & & & 21 \\
\hline Erytnrocytes in urine & positive & & & 14 & & & 11 \\
\hline Protein in urine & negative & & & 7 & & & 13 \\
\hline Protemn in unte & positive & & & 19 & & & 19 \\
\hline Urea $(<50 \mathrm{ml})$ & & 100 & 65 & & 117 & 75 & \\
\hline LDH $(<250)$ & & 226 & 101 & & 250 & 89 & \\
\hline GOT $(<50)$ & & 28 & 28 & & 32 & 39 & \\
\hline GPT $(<50)$ & & 30 & 36 & & 27 & 25 & \\
\hline yGT $(<60)$ & & 83 & 121 & & 65 & 87 & \\
\hline $\mathrm{Hb}(13.5-18)$ & & 10 & 2 & & 10 & 2 & \\
\hline MCHC (31- 37) & & 32 & 4 & & 32 & 3 & \\
\hline Erythroczytes (4.5- 5.9 & & 4 & 1 & & 4 & 5 & \\
\hline $\mathrm{HbA1c}(4.8-6.0)$ & & 6 & 1 & & 6 & 1 & \\
\hline $\mathrm{CRP}(<5.0 \mathrm{mg} / \mathrm{l})$ & & 23 & 24 & & 24 & 31 & \\
\hline Erythrocyte sedimenta & on speed $<14 \mathrm{ml} / \mathrm{h}$ ) & 28 & 25 & & 32 & 28 & \\
\hline Tacrolimus $(\mu \mathrm{g} / \mathrm{l})$ & & 377 & 1886 & & 9 & 7 & \\
\hline Cyclosporine A & & 183 & 74 & & 140 & 94 & \\
\hline Sirolimus & & . & . & & 6 & 3 & \\
\hline$A C F$ inhibitor & no & & & 43 & & & 43 \\
\hline ACE InmIDitor & yes & & & 17 & & & 21 \\
\hline Co & no & & & 42 & & & 52 \\
\hline ca-antagonst & yes & & & 18 & & & 12 \\
\hline Diuretic & no & & & 47 & & & 50 \\
\hline Diuretic & yes & & & 13 & & & 14 \\
\hline B_blocker & no & & & 30 & & & 37 \\
\hline D-DIOcker & yes & & & 30 & & & 27 \\
\hline Thyroxin & no & & & 45 & & & 49 \\
\hline 111yioxin & yes & & & 0 & & & 0 \\
\hline РTH & no & & & 45 & & & 49 \\
\hline РТН & yes & & & 0 & & & 0 \\
\hline $\mathrm{FPO}$ & no & & & 49 & & & 57 \\
\hline EPU & yes & & & 11 & & & 7 \\
\hline
\end{tabular}




\begin{tabular}{|c|c|c|c|}
\hline \multirow{2}{*}{ Bisphosphonate } & no & 45 & 49 \\
\hline & yes & 0 & 0 \\
\hline \multirow{2}{*}{ Antibiotics } & no & 45 & 49 \\
\hline & yes & 0 & 0 \\
\hline \multirow{4}{*}{$\begin{array}{l}\text { Immuno- } \\
\text { suppressives }\end{array}$} & Tacrolimus & 28 & 23 \\
\hline & СуA & 17 & 19 \\
\hline & Sirolimus & 0 & 0 \\
\hline & both & 2 & 4 \\
\hline
\end{tabular}

LDH: Llactate dehydrogenase; y GT: y glutamyl-transferase; GOT: Glutamic oxaloacetate transaminase; GPT: Glutamic pyruvate transaminase; MCHC: Mean corpuscular hemoglobin concentration; CRP: C-reactive protein

protocol. RNA quantification was accomplished using the NanoDrop technology. miRNA from cell culture experiments was isolated with the PureLink miRNA isolation kit from Invitrogen according to the manufacturer's protocol. miRNA was quantified using the NanoDrop technology [16].

\section{RT-PCR for miRNA}

The cDNA was obtained from 100 ng template RNA using the miScript II RT kit from Qiagen using $5 x$ High Spec buffer. In order to bein the semi-quantitative range, theamountofcDNA was previously determined by titration and the number of PCR cycles was standardized. The RT-PCR was performed at $37^{\circ} \mathrm{C}$ for 60 minutes followed by $95^{\circ} \mathrm{C}$ for 5 minutes according to the manufacturer's protocol. The PCR reactions were performed in a final volume of $25 \mu \mathrm{l}$. For analysis of the PCR product $2.5 \%$ agarose gels were performed and were run in $1 \times$ TAE buffer [15].

\section{Quantitative real-time PCR (qRT-PCR) for miRNA}

$1 \mu \mathrm{l}$ of the aforementioned cDNA was employed for realtime PCR analysis. The primers used were: miRNA 133a, forward: UUUGGUCCCCUUCAACCAGCUG, temp $50^{\circ} \mathrm{C}$; $5 \mathrm{~s}$ rRNA forward: GAAUUGCAAGCCACCUGUUG, temp $50^{\circ} \mathrm{C}$. The MystiCq Universal PCR Primer (Sigma-Aldrich) served as a reverse universal primer. The primer for $5 \mathrm{~s}$ ribosomal RNA was employed to normalize results among different samples for miRNA evaluation. The experimental settings were as described previously. All experiments were done in triplicates; 55 PCR cycles. Relative fluorescence was calculated using the $\Delta \Delta C T$ method as outlined in User Bulletin 2 (PE Applied Biosystems) [15]. Control biopsies for the CyA study (six cases of normal renal tissue from tumor resection specimens; Table 5) were used to calculate the ddct-values.

\section{Statistics}

To compare clinical data sets, these were transfered into the IBM SSS Statistics program, and analyzed for mean and standard deviation; plus subjected to a Levene's test (variance homogeneity), a $t$-test, and a Pearson's Chi-square test, respectively. Graphpad Prism 5.0 (Graph-Pad Software, La Jolla, USA) was used for statistics of qRTPCR analyses in triplicates at different time points, assessed by the Bonferroni method based on one-way analysis of variance (ANOVA). Morphometric data was performed in triplicates. Differences were calculated by the Newman-Keuls method $\left({ }^{*} \mathrm{p}<0.05,{ }^{* *} \mathrm{p}<0.01\right.$, $\left.{ }^{* * *} p<0.001\right)$. All unmarked results were not statistically significant. Differences between groups were analyzed by unpaired $t$-test.

\section{Results}

\section{Detection of MRP-2 and miRNA133a in cultured RPTECs}

In comparison to control cells, MRP-2 was downregulated by $40 \%$ after ET-1 treatment for $72 \mathrm{hrs}$. Combined with CyA, ET- 1 reduced the
MRP-2 to $50 \%$ of the control level (Figure 1A). The qRT-PCR analysis for miRNA133a showed a clear increase in miR133a levels versus controls (used as calculation reference), the value being doubled after the combined treatment of ET-1 with CyA (Figure 1B).

\section{Cyclosporin A cytotoxicity: MRP2 vs. miRNA133a expression}

a. Classification of CyA treated renal transplant cases used and their clinical data: Reevaluating routinely diagnosed renal biopsies treated with CyA enabled the establishment of four major groups according to the BANFF 2007 classification (Table 1): i.e., no damage, arteriolar damage, tubular damage, and combined arteriolar plus tubular damage. Subsequently, the clinical data of three categories (i.e. clinical parameters, laboratory values, and medications) were collected and statistically analyzed (Table 4). This evaluation (Table 5) showed that the age variant in all groups was not statistically different (F.01,2,80=2.39; F=0.02). However, in all groups the levels of CyA were elevated despite of strict blood level control. Furthermore, the erythrocyte counts were low (on average $4 \times 10^{6}$; norm $4.5 \times 10^{6}-5 \times 10^{6}$ ).

The control group being subjected to CyA treatment without observed damage was characterized by younger patients with lower creatinine values, where a rejection was assumed. In contrast, patients belonging to the group with tubular damage, the diagnoses were confirmed within $24 \mathrm{~d}$, having the highest creatinine values of all groups, on average about $6 \mathrm{mg} / \mathrm{dl}$. Also, CyA values were higher than in the other groups (on average $194 \mathrm{mg} / \mathrm{dl}$ ). In patients with an arteriolar damage, transplantation was caused by different renal comorbidities such as a chronic glomerulonephritis, ADPKD, or tumor infiltration. Functionally, they displayed the highest creatinine (above $3.2 \mathrm{mg}$ / dl) and urea levels of all groups. However, the diagnosis was reached at a late stage after transplantation (mean $720 \mathrm{~d}$ ). The group having arteriolar and tubular damage had no distinct clinical characteristics. Comparing all groups regarding statistical significance of potentially predicting values for CyA toxicity, analysis of the $t$-test did not yield a p-value below 0.05 for any of the clinical or medication parameters or for the laboratory values observed (Table 6). The frequency distribution measured by Pearson's $\chi^{2}$ testing was not below 0.05 ; thus, the null hypothesis had to be rejected (Table 7).

\section{Morphologically observed changes}

The analysis of CyA damage regarding proximal tubules showed by routine H\&E staining typical hydropic swelling with loss of brush border. This so-called osmotic nephrosis (Figure 2A), however, was observed in different degrees, varying from nephron to nephron in a biopsy. Focally, there was a nest-like accumulation of tubules with such changes, while in other locations only individual cells were damaged (Figure 2A). Importantly, maintained brush border did not always show MRP2 expression by immune histology (Figure 2B; black arrow). On the other hand, a tubule could show a hydropically swollen tubular cells 
Table 6. Statistical analysis of parameters

\begin{tabular}{|c|c|c|c|c|c|c|c|c|c|c|}
\hline \multicolumn{6}{|l|}{ LEVENE Test } & \multicolumn{5}{|c|}{ t-Test } \\
\hline & $\mathbf{F}$ & sig & $\mathbf{t}$ & df & Sig (2 sides) & mean diff. & std & std error diff. & lower & upper \\
\hline Age & $\begin{array}{l}\text { Yes } \\
\text { No }\end{array}$ & 0.646 & 0.423 & $\begin{array}{l}-1.922 \\
'-1.921\end{array}$ & $\begin{array}{c}122 \\
121.238\end{array}$ & $\begin{array}{l}0.057 \\
0.057\end{array}$ & $\begin{array}{l}-5.654 \\
\\
\end{array}$ & \begin{tabular}{|l|}
2.942 \\
2.943 \\
\end{tabular} & $\begin{array}{l}-11.478 \\
'-11.481\end{array}$ & $\begin{array}{l}0.189 \\
0.172\end{array}$ \\
\hline $\begin{array}{l}\text { Transplantation } \\
\text { Survival (d) }\end{array}$ & $\begin{array}{l}\text { Yes } \\
\text { No }\end{array}$ & 0.172 & 0.679 & $\begin{array}{l}-0.179 \\
'-0.179\end{array}$ & $\begin{array}{c}99 \\
98.007\end{array}$ & $\begin{array}{l}0.859 \\
0.859\end{array}$ & $\begin{array}{l}-60.239 \\
-60.239\end{array}$ & $\begin{array}{l}337.409 \\
337.002\end{array}$ & $\begin{array}{l}-729.721 \\
'-729.721\end{array}$ & $\begin{array}{l}609.263 \\
608.540\end{array}$ \\
\hline Gender & $\begin{array}{l}\text { Yes } \\
\text { No }\end{array}$ & 3.347 & 0.068 & $\begin{array}{l}0.926 \\
0.928\end{array}$ & $\begin{array}{c}122 \\
121.996\end{array}$ & $\begin{array}{l}0.356 \\
0.356\end{array}$ & $\begin{array}{l}0.077 \\
0.077\end{array}$ & $\begin{array}{l}0.083 \\
0.083\end{array}$ & $\begin{array}{l}-0.088 \\
'-0.087\end{array}$ & $\begin{array}{l}0.242 \\
0.241\end{array}$ \\
\hline $\begin{array}{l}\text { Rejection } \\
\text { damage }\end{array}$ & $\begin{array}{l}\text { Yes } \\
\text { No }\end{array}$ & 3.881 & 0.051 & $\begin{array}{l}1.013 \\
1.011\end{array}$ & $\begin{array}{c}122 \\
120.047\end{array}$ & $\begin{array}{l}0.313 \\
0.314\end{array}$ & $\begin{array}{l}0.086 \\
0.086\end{array}$ & $\begin{array}{l}0.085 \\
0.086\end{array}$ & $\begin{array}{l}-0.083 \\
'-0.083\end{array}$ & $\begin{array}{l}0.255 \\
0.256\end{array}$ \\
\hline $\begin{array}{l}\text { body length } \\
(\mathrm{cm})\end{array}$ & $\begin{array}{l}\text { Yes } \\
\text { No }\end{array}$ & 0.40 & 0.843 & $\begin{array}{l}1.152 \\
1.499\end{array}$ & $\begin{array}{c}64 \\
59.385\end{array}$ & $\begin{array}{l}0.135 \\
0.139\end{array}$ & $\begin{array}{l}3.689 \\
3.689\end{array}$ & $\begin{array}{l}2.440 \\
2.461\end{array}$ & $\begin{array}{l}-1185 \\
'-1.235\end{array}$ & $\begin{array}{l}8.563 \\
8.612\end{array}$ \\
\hline $\begin{array}{l}\text { Body weight } \\
\text { (kg) }\end{array}$ & $\begin{array}{l}\text { Yes } \\
\text { No }\end{array}$ & 0.052 & 0.820 & $\begin{array}{l}1.658 \\
1.659\end{array}$ & $\begin{array}{c}71 \\
70.935\end{array}$ & $\begin{array}{l}0.102 \\
0.102\end{array}$ & $\begin{array}{l}5.754 \\
5.754\end{array}$ & $\begin{array}{l}3.471 \\
3.471\end{array}$ & $\begin{array}{l}-1.168 \\
'-1.162\end{array}$ & $\begin{array}{l}12.676 \\
12.671\end{array}$ \\
\hline RRSys & $\begin{array}{l}\text { Yes } \\
\text { No }\end{array}$ & 0.021 & 0.886 & $\begin{array}{l}0.561 \\
0.563\end{array}$ & $\begin{array}{c}23 \\
23.000\end{array}$ & $\begin{array}{l}0.580 \\
0.579\end{array}$ & $\begin{array}{l}5.071 \\
5.071\end{array}$ & $\begin{array}{l}9.042 \\
9.010\end{array}$ & $\begin{array}{l}-13.633 \\
-13.568\end{array}$ & $\begin{array}{l}23.774 \\
23.709\end{array}$ \\
\hline $\begin{array}{l}\text { RR } \\
(\mathrm{mmHg})\end{array}$ & $\begin{array}{l}\text { Yes } \\
\text { No }\end{array}$ & 0.532 & 0.473 & $\begin{array}{l}0.401 \\
0.403\end{array}$ & $\begin{array}{c}23 \\
22.900\end{array}$ & $\begin{array}{l}0.692 \\
0.693\end{array}$ & $\begin{array}{l}2.378 \\
2.378\end{array}$ & $\begin{array}{l}5.938 \\
5.901\end{array}$ & $\begin{array}{l}-9905 \\
'-9.832\end{array}$ & $\begin{array}{l}14.661 \\
14.588\end{array}$ \\
\hline RRMedisSys & $\begin{array}{l}\text { Yes } \\
\text { No }\end{array}$ & 0.000 & 0.939 & $\begin{array}{l}0.547 \\
0.548\end{array}$ & $\begin{array}{c}53 \\
52.727 \\
\end{array}$ & $\begin{array}{l}0.587 \\
0.586\end{array}$ & $\begin{array}{l}3.718 \\
3.718\end{array}$ & $\begin{array}{l}6.794 \\
6.779\end{array}$ & $\begin{array}{l}-9.910 \\
'-9.881\end{array}$ & $\begin{array}{l}17.345 \\
17.316\end{array}$ \\
\hline RR unter Medis & $\begin{array}{l}\text { Yes } \\
\text { No }\end{array}$ & 0.996 & 0.323 & $\begin{array}{l}0.770 \\
0.766\end{array}$ & $\begin{array}{c}53 \\
50.892\end{array}$ & $\begin{array}{l}0.445 \\
0.447\end{array}$ & $\begin{array}{l}3.320 \\
3.320\end{array}$ & $\begin{array}{l}4.313 \\
4.335\end{array}$ & $\begin{array}{l}-5.332 \\
-5.385\end{array}$ & $\begin{array}{l}11.971 \\
12.024\end{array}$ \\
\hline DM & $\begin{array}{l}\text { Yes } \\
\text { No }\end{array}$ & 0.364 & 0.547 & $\begin{array}{l}-0.301 \\
'-0.302 \\
\end{array}$ & $\begin{array}{c}122 \\
121.954\end{array}$ & $\begin{array}{l}0.764 \\
0.763\end{array}$ & $\begin{array}{l}-0.021 \\
'-0.021\end{array}$ & $\begin{array}{l}0.069 \\
0-069\end{array}$ & $\begin{array}{l}-0.158 \\
'-0.158\end{array}$ & $\begin{array}{l}0.110 \\
0.110\end{array}$ \\
\hline $\begin{array}{l}\text { Adipositas } \\
(\mathrm{BMI}>30)\end{array}$ & $\begin{array}{l}\text { Yes } \\
\text { No }\end{array}$ & 0.114 & 0.736 & $\begin{array}{l}-0.169 \\
'-0.169\end{array}$ & $\begin{array}{c}122 \\
121.917\end{array}$ & $\begin{array}{l}0.866 \\
0.866\end{array}$ & $\begin{array}{l}-0.009 \\
'-0.009\end{array}$ & $\begin{array}{l}0.055 \\
0.055\end{array}$ & $\begin{array}{l}-0.119 \\
'-0.119\end{array}$ & $\begin{array}{l}0.100 \\
0.100\end{array}$ \\
\hline $\begin{array}{l}\text { Hypercholest. } \\
(>200 \mathrm{mg} / \mathrm{dl})\end{array}$ & $\begin{array}{l}\text { Yes } \\
\text { No }\end{array}$ & 0.001 & 0.978 & $\begin{array}{l}-0.014 \\
'-0.014\end{array}$ & $\begin{array}{c}122 \\
121.51\end{array}$ & $\begin{array}{l}0.989 \\
0.989\end{array}$ & $\begin{array}{l}-0.001 \\
'-0.001\end{array}$ & $\begin{array}{l}0.077 \\
0.077\end{array}$ & $\begin{array}{l}-0.153 \\
-0.153\end{array}$ & $\begin{array}{l}0.151 \\
0.151\end{array}$ \\
\hline $\begin{array}{l}\text { Creatinine } \\
(0.5-1.1 \mathrm{mg} / \mathrm{dl})\end{array}$ & $\begin{array}{l}\text { Yes } \\
\text { No }\end{array}$ & 3.013 & 0.085 & $\begin{array}{l}-0.913 \\
'-0.913\end{array}$ & $\begin{array}{c}107 \\
102.922\end{array}$ & $\begin{array}{l}0.384 \\
0.384\end{array}$ & $\begin{array}{l}-0.31896 \\
'-0.31896\end{array}$ & $\begin{array}{l}-0.34953 \\
'-0.34709\end{array}$ & $\begin{array}{l}-1.01197 \\
'-1.00733\end{array}$ & $\begin{array}{l}0.37395 \\
0.36941\end{array}$ \\
\hline StixGlukose & $\begin{array}{l}\text { Yes } \\
\text { No }\end{array}$ & 0.174 & 0.678 & $\begin{array}{l}0.209 \\
0.207\end{array}$ & $\begin{array}{c}59 \\
55.726\end{array}$ & $\begin{array}{l}0.835 \\
0.836\end{array}$ & $\begin{array}{l}0.016 \\
0.016\end{array}$ & $\begin{array}{l}0.078 \\
0.078\end{array}$ & $\begin{array}{l}-0.139 \\
'-0.141\end{array}$ & $\begin{array}{l}0.172 \\
0.173\end{array}$ \\
\hline StixErys & $\begin{array}{l}\text { Yes } \\
\text { No }\end{array}$ & 2.929 & 0.092 & $\begin{array}{l}1.219 \\
1.215\end{array}$ & $\begin{array}{c}58 \\
55.994 \\
\end{array}$ & $\begin{array}{l}0.228 \\
0.229\end{array}$ & $\begin{array}{l}0.156 \\
0.156\end{array}$ & $\begin{array}{l}0.128 \\
0.129\end{array}$ & $\begin{array}{l}-0.100 \\
-0.101\end{array}$ & $\begin{array}{l}0.413 \\
0.414\end{array}$ \\
\hline Protein Stix & $\begin{array}{l}\text { Yes } \\
\text { No }\end{array}$ & 4.668 & 0.035 & $\begin{array}{l}1.084 \\
1.085\end{array}$ & $\begin{array}{c}56 \\
55.288\end{array}$ & $\begin{array}{l}0.283 \\
0.278\end{array}$ & $\begin{array}{l}0.137 \\
0.137\end{array}$ & $\begin{array}{l}0.126 \\
0.125\end{array}$ & $\begin{array}{l}-0.116 \\
'-0.114\end{array}$ & $\begin{array}{l}0.390 \\
0.388\end{array}$ \\
\hline $\begin{array}{l}\text { Harnstoff } \\
(<50 \mathrm{ml})\end{array}$ & $\begin{array}{l}\text { Yes } \\
\text { No }\end{array}$ & 2.694 & 0.104 & $\begin{array}{l}-1.120 \\
'-1.124\end{array}$ & $\begin{array}{c}90 \\
89.165\end{array}$ & $\begin{array}{l}0.266 \\
0.264\end{array}$ & $\begin{array}{l}-16.475 \\
'-16.475\end{array}$ & $\begin{array}{l}14.707 \\
14.662 \\
\end{array}$ & $\begin{array}{l}-45,694 \\
'-45.608\end{array}$ & $\begin{array}{l}12.744 \\
12.657\end{array}$ \\
\hline \begin{tabular}{|l} 
LDH \\
$(<250)$
\end{tabular} & $\begin{array}{l}\text { Yes } \\
\text { No }\end{array}$ & 0.228 & 0.638 & $\begin{array}{l}-1.127 \\
-1.140\end{array}$ & $\begin{array}{c}82 \\
81.613\end{array}$ & $\begin{array}{l}0.262 \\
0.257\end{array}$ & $\begin{array}{l}-23.677 \\
-23.677\end{array}$ & $\begin{array}{l}21.012 \\
20.762\end{array}$ & $\begin{array}{l}-65.477 \\
'-64.983\end{array}$ & $\begin{array}{l}18.122 \\
17.629\end{array}$ \\
\hline $\begin{array}{l}\text { GOT } \\
(<50)\end{array}$ & $\begin{array}{l}\text { Yes } \\
\text { No }\end{array}$ & 1.062 & 0.308 & $\begin{array}{l}-0.615 \\
'-0.611\end{array}$ & $\begin{array}{c}92 \\
80,674\end{array}$ & $\begin{array}{l}0.540 \\
0.543\end{array}$ & $\begin{array}{l}-4.285 \\
-4.285\end{array}$ & $\begin{array}{l}6.967 \\
7.017\end{array}$ & $\begin{array}{l}-18.122 \\
'-18.248\end{array}$ & $\begin{array}{l}9.551 \\
9.677\end{array}$ \\
\hline $\begin{array}{l}\text { GPT } \\
(<50)\end{array}$ & $\begin{array}{l}\text { Yes } \\
\text { No }\end{array}$ & 0.209 & 0.649 & $\begin{array}{l}0.499 \\
0.500\end{array}$ & $\begin{array}{c}93 \\
83.611\end{array}$ & $\begin{array}{l}0.619 \\
0.619\end{array}$ & $\begin{array}{l}3.172 \\
3.172\end{array}$ & $\begin{array}{l}6.302 \\
6.338\end{array}$ & $\begin{array}{l}-9.463 \\
'-9.434\end{array}$ & $\begin{array}{c}15.807 \\
15.7786\end{array}$ \\
\hline $\begin{array}{l}\text { gGT } \\
(<60)\end{array}$ & $\begin{array}{l}\text { Yes } \\
\text { No }\end{array}$ & 2.143 & 0.147 & $\begin{array}{l}0.759 \\
0.770\end{array}$ & $\begin{array}{c}86 \\
81.758\end{array}$ & $\begin{array}{l}0.450 \\
0.444\end{array}$ & $\begin{array}{l}17.234 \\
17.234\end{array}$ & $\begin{array}{l}22.721 \\
22.393\end{array}$ & $\begin{array}{l}-27.933 \\
'-27315\end{array}$ & $\begin{array}{l}62.401 \\
61.783 \\
\end{array}$ \\
\hline $\mathrm{Hb}(13.5-18)$ & $\begin{array}{l}\text { Yes } \\
\text { No }\end{array}$ & 0.139 & $0-710$ & $\begin{array}{l}0.743 \\
0.734\end{array}$ & $\begin{array}{c}104 \\
102.499\end{array}$ & $\begin{array}{l}0.459 \\
0.458\end{array}$ & $\begin{array}{l}0.292 \\
0.292\end{array}$ & $\begin{array}{l}0.393 \\
0.392\end{array}$ & $\begin{array}{l}0.488 \\
0.486\end{array}$ & $\begin{array}{l}1.072 \\
1.070\end{array}$ \\
\hline MCHC (31- 37) & $\begin{array}{l}\text { Yes } \\
\text { No }\end{array}$ & 0.119 & 0.731 & $\begin{array}{l}0.254 \\
0.249\end{array}$ & $\begin{array}{c}88 \\
74.240\end{array}$ & $\begin{array}{l}0.800 \\
0.804\end{array}$ & $\begin{array}{l}0.206 \\
0.206\end{array}$ & $\begin{array}{l}0.811 \\
0.811\end{array}$ & $\begin{array}{l}-1.406 \\
'-1.444\end{array}$ & $\begin{array}{l}1.818 \\
1.856\end{array}$ \\
\hline $\begin{array}{l}\text { Erythrozyten } \\
(4.5-5.9)\end{array}$ & $\begin{array}{l}\text { Yes } \\
\text { No }\end{array}$ & 1.430 & 0.235 & $\begin{array}{l}-0.737 \\
'-0.759\end{array}$ & $\begin{array}{c}97 \\
52.167\end{array}$ & $\begin{array}{l}0.463 \\
0.451\end{array}$ & $\begin{array}{l}-0.493 \\
'-0.493\end{array}$ & $\begin{array}{l}0.670 \\
0.650\end{array}$ & $\begin{array}{l}-1.822 \\
'-1.798\end{array}$ & $\begin{array}{l}0.836 \\
0.811\end{array}$ \\
\hline $\mathrm{HbAlc}(4.8-6.0)$ & $\begin{array}{l}\text { Yes } \\
\text { No }\end{array}$ & 1.651 & 0.209 & $\begin{array}{l}-0.973 \\
'-0.983\end{array}$ & $\begin{array}{c}29 \\
27.268\end{array}$ & $\begin{array}{l}0.339 \\
0.334\end{array}$ & $\begin{array}{l}-0.327 \\
'-0.327\end{array}$ & $\begin{array}{l}0.336 \\
0.333\end{array}$ & $\begin{array}{l}-1.015 \\
'-1.010\end{array}$ & $\begin{array}{l}0.381 \\
0.355\end{array}$ \\
\hline CRP $(<5.0 \mathrm{mg} / \mathrm{l})$ & $\begin{array}{l}\text { Yes } \\
\text { No }\end{array}$ & 1.580 & 0.215 & $\begin{array}{l}-0.169 \\
'-0.169\end{array}$ & $\begin{array}{c}50 \\
47.061\end{array}$ & $\begin{array}{l}0.867 \\
0.867\end{array}$ & $\begin{array}{l}-1.286 \\
'-1.286\end{array}$ & $\begin{array}{l}7.623 \\
7.623\end{array}$ & $\begin{array}{l}-16.597 \\
'-16.621\end{array}$ & $\begin{array}{l}14.025 \\
14.049\end{array}$ \\
\hline BSG $(<14 \mathrm{ml} / \mathrm{h})$ & $\begin{array}{l}\text { Yes } \\
\text { No }\end{array}$ & 0.381 & 0.536 & $\begin{array}{l}-0.380 \\
'-0.378\end{array}$ & $\begin{array}{c}36 \\
32.415 \\
\end{array}$ & $\begin{array}{l}0.706 \\
0.710\end{array}$ & $\begin{array}{l}-3.307 \\
-3.307\end{array}$ & $\begin{array}{l}8.692 \\
8.803\end{array}$ & $\begin{array}{l}-20.935 \\
'-21.228\end{array}$ & $\begin{array}{l}14.321 \\
14.614 \\
\end{array}$ \\
\hline Tacrolimus $(\mu \mathrm{g} / \mathrm{l})$ & $\begin{array}{l}\text { Yes } \\
\text { No }\end{array}$ & 3.646 & 0.062 & $\begin{array}{l}0.965 \\
1.033\end{array}$ & $\begin{array}{c}50 \\
27.001\end{array}$ & $\begin{array}{l}0.344 \\
0.311\end{array}$ & $\begin{array}{l}368.167 \\
368.157\end{array}$ & $\begin{array}{l}385.572 \\
368.167\end{array}$ & $\begin{array}{l}-406.277 \\
--363.232\end{array}$ & $\begin{array}{l}1142.610 \\
1099.585\end{array}$ \\
\hline Cyclosporine & $\begin{array}{l}\text { Yes } \\
\text { No }\end{array}$ & 1.815 & 0.188 & $\begin{array}{l}1.371 \\
1.425 \\
\end{array}$ & $\begin{array}{c}29 \\
28.716\end{array}$ & $\begin{array}{l}0.181 \\
0.181\end{array}$ & $\begin{array}{l}43.218 \\
43.218\end{array}$ & $\begin{array}{l}31.523 \\
30.322\end{array}$ & $\begin{array}{l}-21.254 \\
'-18.824\end{array}$ & $\begin{array}{l}107.690 \\
105.260\end{array}$ \\
\hline ACE inhibitor & $\begin{array}{l}\text { Yes } \\
\text { No }\end{array}$ & 1.157 & 0.284 & $\begin{array}{l}-0.537 \\
'-0.538\end{array}$ & $\begin{array}{c}122 \\
121.927\end{array}$ & $\begin{array}{l}0.592 \\
0.592\end{array}$ & $\begin{array}{l}-0,045 \\
'-0.045\end{array}$ & $\begin{array}{l}0.83 \\
0.83\end{array}$ & $\begin{array}{l}-0.210 \\
'-0.210\end{array}$ & $\begin{array}{l}0.120 \\
0.120\end{array}$ \\
\hline Ca-blocker & $\begin{array}{l}\text { Yes } \\
\text { No }\end{array}$ & 8.525 & 0.004 & $\begin{array}{l}1.463 \\
1.465\end{array}$ & $\begin{array}{c}122 \\
116.180\end{array}$ & $\begin{array}{l}0.146 \\
0.148\end{array}$ & $\begin{array}{l}0.113 \\
0.113\end{array}$ & $\begin{array}{l}0.077 \\
0.077\end{array}$ & $\begin{array}{l}-0,040 \\
'-0.041\end{array}$ & $\begin{array}{l}0.265 \\
0.266\end{array}$ \\
\hline Diuretic & $\begin{array}{l}\text { Yes } \\
\text { No }\end{array}$ & 0.003 & 0.954 & $\begin{array}{l}-0.028 \\
'-0.028\end{array}$ & $\begin{array}{c}122 \\
121.530\end{array}$ & $\begin{array}{l}0.978 \\
0.978\end{array}$ & $\begin{array}{l}-0.002 \\
'-0.002\end{array}$ & $\begin{array}{l}0.075 \\
0.075\end{array}$ & $\begin{array}{l}-0.150 \\
'-0-150\end{array}$ & $\begin{array}{l}0.146 \\
0.146\end{array}$ \\
\hline
\end{tabular}




\begin{tabular}{|l|c|c|c|c|c|c|c|c|c|c|}
\hline \multirow{2}{*}{ Beta-Blocker } & Yes & \multirow{2}{*}{1.477} & 0.277 & 0.868 & 122 & 0.387 & 0.078 & 0.090 & -0.100 & 0.256 \\
& No & & & 0.868 & 121.263 & 0.387 & 0.078 & 0.090 & -0.100 & 0.256 \\
\hline EPO & Yes & \multirow{2}{*}{5.582} & 0.020 & 1.165 & 122 & 0.246 & 0.074 & 0.063 & -0.052 & 0.200 \\
& No & & & 1.157 & 113.382 & 0.250 & 0.074 & 0.064 & $'-0.053$ & 0.201 \\
\hline Immuno- & Yes & \multirow{2}{*}{0.832} & 0.364 & -1.116 & 91 & 0.267 & -0.185 & 0.165 & -0.513 & 0.144 \\
suppression & No & & & -1.114 & 87.118 & 0.268 & -0.185 & 0.165 & -0.514 & 0.145 \\
\hline
\end{tabular}

LDH: Lactate dehydrogenase; Ygt: y glutamyl-transferase; GOT: Glutamic oxaloacetate transaminase; GPT: Glutamic pyruvate transaminase; MCHC: Mean corpuscular hemoglobin concentration; CRP: C-reactive protein

Table 7. Chi-Quadrat-Tests nach Pearson

\begin{tabular}{|l|c|c|c|}
\hline & $\chi^{\mathbf{2}}$ & Df & Sig. \\
\hline Gender & 0.865 & 1 & 0.352 \\
\hline Rejection & 1033 & 1 & 0.309 \\
\hline Diabetes mellitus & 0.092 & 1 & 0.762 \\
\hline Obesity & 0.029 & 1 & 0.865 \\
\hline Hypercholesterinemia & 0.000 & 1 & 0.969 \\
\hline ACE inhibitors & 0.292 & 1 & 0.589 \\
\hline Ca-antagonists & 2137 & 1 & 0.144 \\
\hline Diuretics & 0.001 & 1 & 0.379 \\
\hline beta-Blockers & 0.761 & 1 & 0.383 \\
\hline EPO & 1365 & 1 & 0.243 \\
\hline Immunosuppression & 1257 & 1 & 0.533 \\
\hline
\end{tabular}

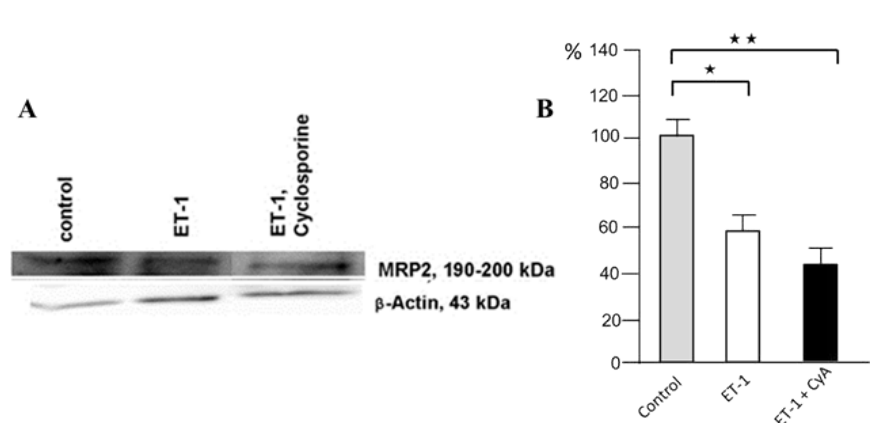

Figure 1A. RPTEC in culture being ET-1/ET-1 + CyA pretreated. Left part of figure, MRP-2 levels by Western blot in control, unstimulated cells, after ET- stimulation and after a combined ET- and CyA stimulation. The right part of figure shows a densitometric analysis of the Western blot with a reduction of MRP2 to $60 \%$ by ET- 1 alone and to $70 \%$ in combination with CyA treatment.

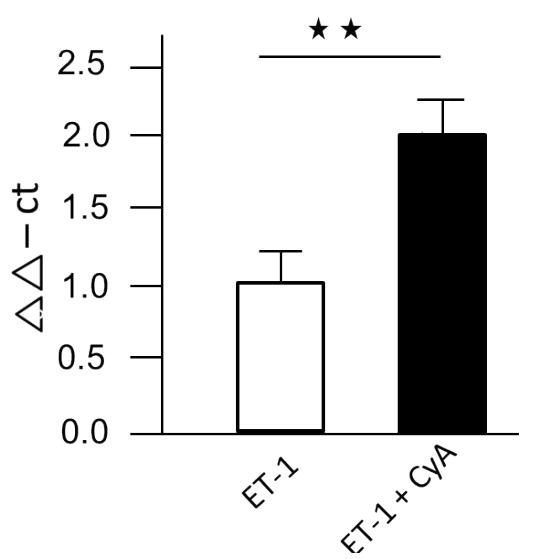

Figure 1B. qRT-PCR for miRNA133a with an $100 \%$ increase in the levels for miRNA133a after ET-1 pretreatment vs. controls (used for calculation) and a more than 200-fold increase after ET-1 plus CyA pretreatment

but still show a MRP2 positivity in the preserved brush border (Figure 2B; green arrow), indicating that the damage had not yet completely destroyed the cell. This high variation makes it very difficult to define the degree of brush border with MRP2 loss without quantification. Arteriolar damage was identified by nodular appearing hyalinosis of arteriolar vessel walls being disseminated and variable between individual arterioles with different degree of severity (data not shown).

\section{Morphologic evaluation MRP2 - expression after CyA treatment vs. controls}

To validate the number of tubules which could be used to analyze for brush border integrity, a PAS staining was obtained, and the respectivenumber of tubules counted. The number of tubules from socalled null biopsies, and from the normal tissue obtained from tumor resection was on average 80 . Repeating the analysis for MRP2, values were slightly lower for CyA-undamaged, combined arteriolar/tubular damaged und null-biopsies but still always above 60 (unpublished data).

To semi-quantitatively group the degree of MRP2 loss at the level of brush border, a graduation system was used consisting of four subdivisions of brush border preservation: i.e., $100 \%,>50 \%,<50$ and $0 \%$.

Using this grading system, in a total of 36 cases the expression of MRP2 was investigated by box plot analysis (Figure 3) followed by one-way ANOVA to determine the intra- versus intervariability of the number of tubules with MRP2 staining according to the individual damage group. As the F-values show (Table 5), there was a highly statistically significant difference at the $p<0.01$ level between the groups with different types of damage and the controls (normal renal tissue from benign tumor resection specimens). The highest degree of MRP2 loss was observed in the group tubular damage followed by the arteriolar damage. The group of combined arteriolar and tubular change did not exceed the ones observed in the arteriolar group alone; however, this was based on only 5 cases. Even in the group, which did not show obvious CyA damage, there was a distinct difference to the controls although the overall loss of MRP2 was expectedly less than in any other group.

The control group of so-called null biopsies from transplant kidneys without timely allocation were the least well preserved of all showing an overall high loss of stainable brush border, particularly with a mean of $44,7 \%$ in the group of $<50 \% \mathrm{MRP} 2$ staining. Since this result in comparison to the renal tissue from the resection specimens had to be considered a post-biopsy event, this group was not chosen as control (see miRNA133a levels).

\section{Levels of mrp2 gene and miRNA133a by qRT-PCR}

To obtain results of a qRT-PCR analysis of the mrp2 gene and miRNA133 the identical cases were used. Figure 4A shows a high amount of mrp2 cDNA being generated after arteriolar damage, while the amount was low in tubular damage, in non-detectable damaged tissue after $\mathrm{Cy} A$, and in all control cases (of renal tissue from resection) InFigure4B, thelevels of miRNA133a for arteriolarvs. tubulardamage are reversed in comparison to the ones measuring MRP2. While there is only a relatively small amount of miRNA133a activated in arteriolar damage, the tubular damage shows an overall marked increase of miRNA133a. Again, cases without recognizable damage and all controls have minimal miRNa133a activation. The amount of miRNA133a from the null-biopsies is very low (data not shown), supporting the 


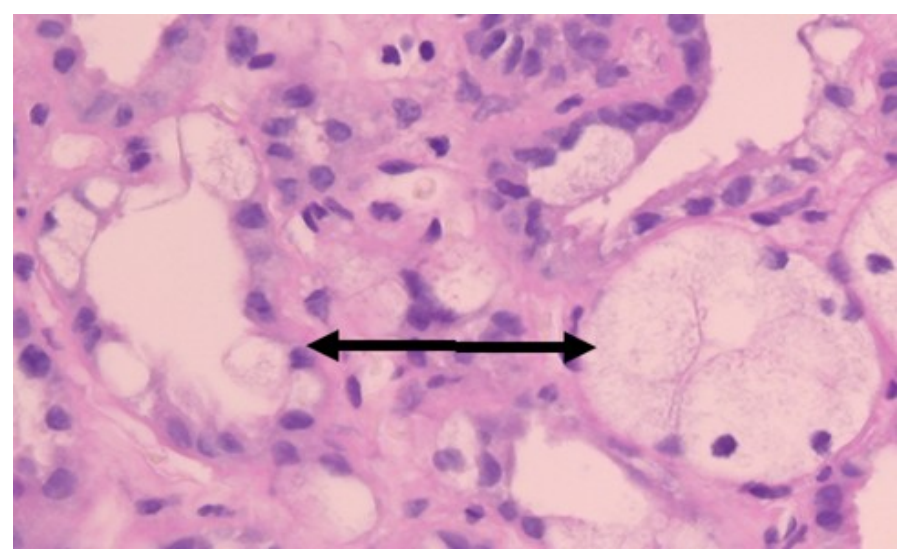

Figure 2A. Light microscopic image of isometric vacuolization involving single cells versus the entire tubular circumference. H\&E staining

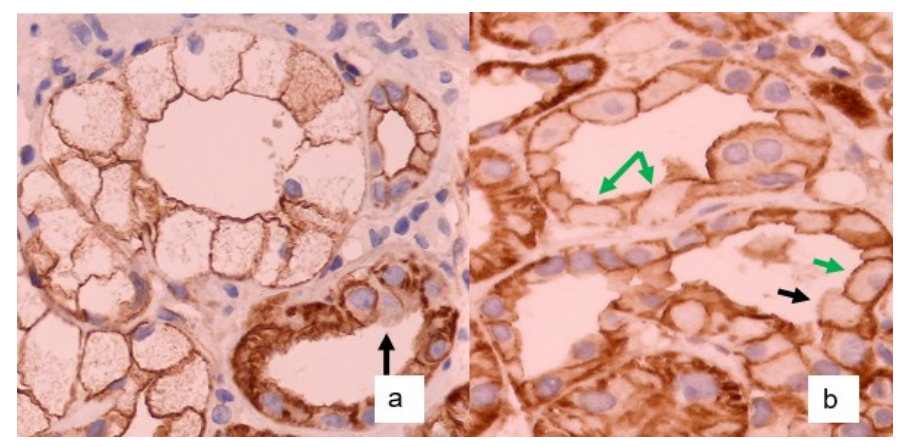

Figure 2B. Immune histology of MRP2 staining. The black arrows show isometric vacuolization with loss of brush border and MRP staining. The green arrows indicate isometric vacuolization with preserved detection of a MRP2 positive brush border.

Magnification in both 1:400

interpretation that this did not represented an invivo but a post-biopsy ischemia alteration. Thus, normal renal tissue from tumor resection specimens with overall well preserved MRP2 detectability was used as reference to calculate the ddct values in Figure $4 \mathrm{~A}$ and $\mathrm{B}$.

\section{Discussion}

The present publication describes the loss of detectability of MRP2 in cases with and without Cyclosporine A toxicity as well as in cell culture versus upregulated miRNA133a levels as pathogenetic mechanism.

MRP2 has been shown to transport toxins and carcinogens into the supernate from renal proximal tubular cells [17], among them cyclosporine A $[18,19]$. CyA has been widely used as an immunosuppressant since the 1980s and has yielded highly improved transplant survival [20]. However, in clinical practiceit proved to have a small therapeutic window and leading to serious therapeutic side effects [21,22] necessitating so-called C2-monitoring [23,24]. To show the effect of ET-1 with/without the combination of CyA, we analyzed RPTECs in culture. By Western blot of MRP2 (Figure 1A) and by qRTPCR of miRNA133a (Figure 1B) we demonstrated that MRP2 and the miRNA is inversely correlated. This is even more enhanced, if CyA is added as pretreatment. In agreement with our previous report in human proteinuric disease [25], we have again found that miRNA133a is an important regulator of MRP2 expression.

The damage caused by CyA can be observed inspite of strict therapeutic controls, leading to acute toxicity [26], which is then histologically typically characterized by an arteriolar (necrosis, hyalinosis) and/ or tubular damage (isometric vacuolisation) [27]. Several months after transplantation and progressing as the lifetime of the transplant continues [28], chronic transplant nephropathy develops, and correlates in its severity with the lifetime of the transplant, affecting all three renal structures (i.e., glomeruli, vessels, and tubules). Besides the hyaline arteriolopathy [29], a streak-like interstitial fibrosis extending into the medullary rays, tubular atrophy (IFTA), and eggshell-like calcifications are observed [30]. Wehypothesized that this distinct morphologic damage should be associated with characteristic clinical changes helping to identify patients at risk.

Thus, our analysis of different clinical parameters, laboratory values, and medications (Table 4) was targeted to detect one or more factors as being eye-catching and proving to be of exceptional value in the pathophysiological understanding of the development of the different degrees of damaged vs. undamaged transplant kidneys. However, in spite of collecting data from 124 patients with 230 biopsies (Table 1) of which 107 were evaluated with the parameters as listed in Table 4, statistical analysis did not yield any significant results but rather a tendential significance only (Tables 6 and 7). This may be due to the fact that this was based on results from a single center study that proved too small to be statistically significant, while to our knowledge, it was the first of such studies being done. To date, factors influencing the outcome of renal transplants have been the so-called cold ischemia time of more than 20 hours, the number of HLA mismatches [31] and the patients' gender. We could confirm the negative influence of cold ischemia and the lifetime of the transplant as potentially causing more arteriolar damage. As an aggravating factor, we found that blood CyA levels were high despite being strictly controlled. Abnormal lab values such as high levels of urea were found, particularly in the group with arteriolar damage. Low erythrocyte counts were detected in all groups. From these investigations, it can be surmised that CyA damage seems to be due to the interplay of different factors and the duration of drug intake over time. However, tubular toxicity leading to renal dysfunction is expectantly one of the most serious side effects of CyA treatment.

Tubular toxicity is an easily noticeable damage identified by its isometric vacuolization [27] in renal biopsies (Figure 2A). Since König, et al. [9] and El-Sheikh, et al. [32] demonstrated that CyA directly inhibited MRP2, we analyzed the degree of MRP2 loss in human biopsies from patients pretreated with CyA. Theintention was to find a correlation with the type of damage (arteriolar vs. tubular), and to define its degree by evaluating semi-quantitatively MRP2 expression in cross-sectioned tubules of renal biopsies (Figure 3) using 4 subcategories. Reasons which made this evaluation more difficult than anticipated were several: (i) the occurrence of loss of brush border in single, individual cells while others having an intact brush border in a cross section; a damage type, which is not readily visualised in its importance in routine diagnostics ; (ii) an MRP2 loss of staining while the brush border is still recognizable by light microscopy, not being detected without immune histology (Figure 2A and B), and (iii) evaluating cross-sections of tubules, we counted all tubules without visible MRP2 staining as damaged. It is not possible, however, to differentiate in the individual case, whether this loss of staining is due to ischemia/autolysis or due to miRNA133a induced downregulation. This could also cause an overestimation of the number of MRP2 losses, since supravitally changes immediately before fixation leading to blabbing and brush border loss are known to occur [33]. Thus, the damage inflicted by CyA does not only affect whole cross sections but also individual cells, which prevents an easy overall evaluation of the degree of tubular damage in routine diagnostics without morphometry. 

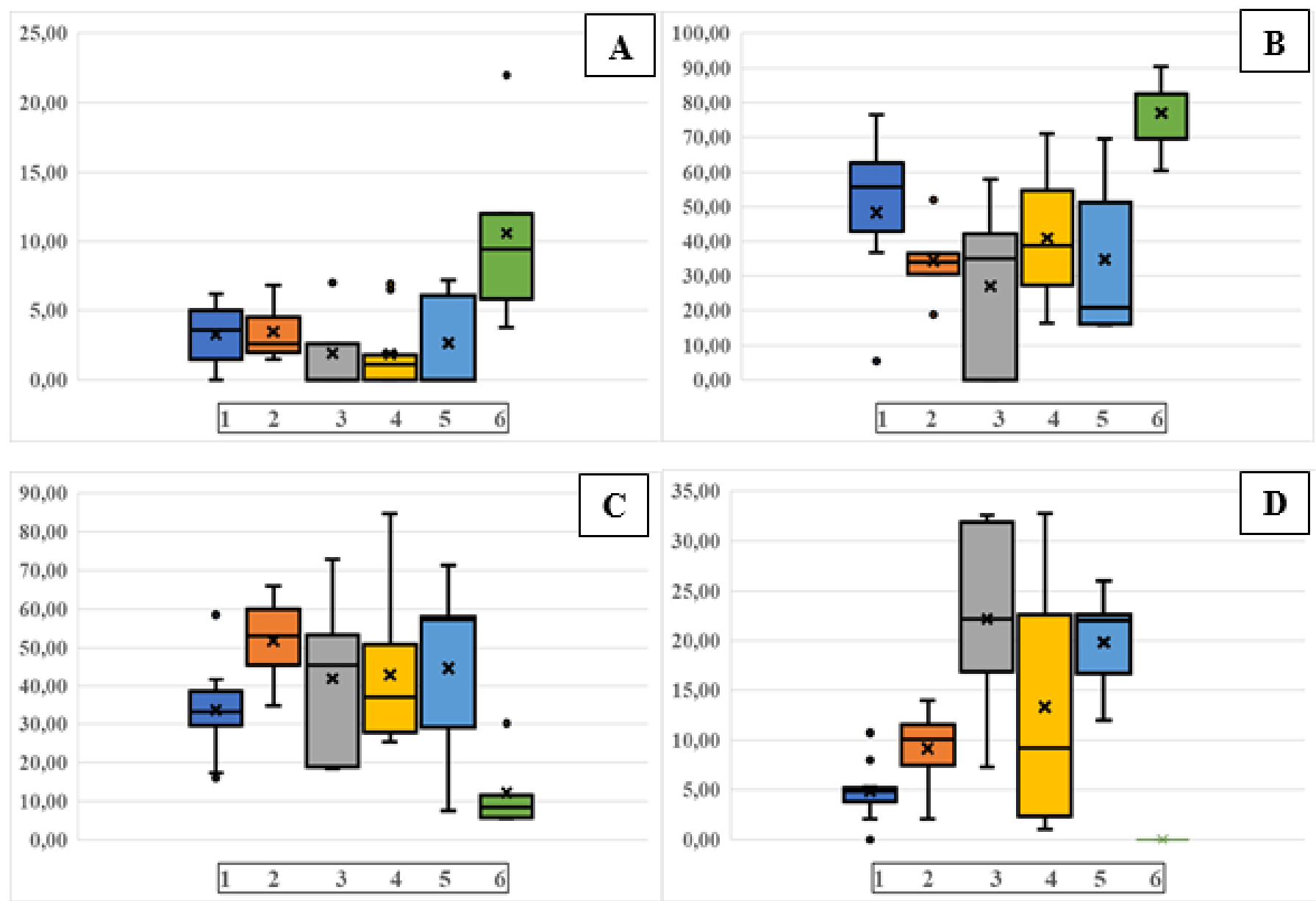

Figure 3. Morphometric analysis of MRP2 positive brush border in groups of patients with different degrees of CyA damage or without CyA damage. A: MRP $=100 \%$; $\mathrm{B}$ : MRP $2>50 \%$; $\mathrm{C}$ : MRP2 $<50 \%$; D: MRP2=0\%. Patient group 1: no damage; Patient group 2: arteriolar damage; Patient group 3: combined arteriolar and tubular damage; Patient group 4: tubular damage; Patient group 5: null biopsies; Patient group 6: controls of normal renal tissue after benign tumor resection (Oncocytoma). Bar=median; $\mathrm{x}=$ mean value; lower and upper quartiles, and lower and upper extreme with whiskers are shown. black dots=statistical outliers

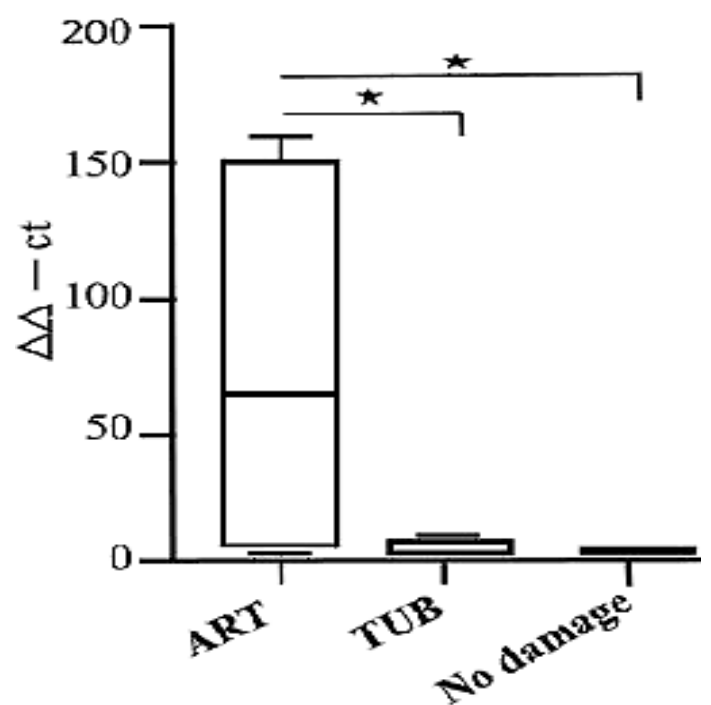

Figure 4A. Analysis of MRP2 in renal biopsies with CyA damage (arteriolar; tubular); no damage as controls. Values from normal renal tissue of tumor resection specimens served to calculate ddet values $\left({ }^{*} \mathrm{p}<0.05, * * \mathrm{p}<0.01\right)$

Nephrol RenalDis, $2020 \quad$ doi: 10.15761/NRD.1000166

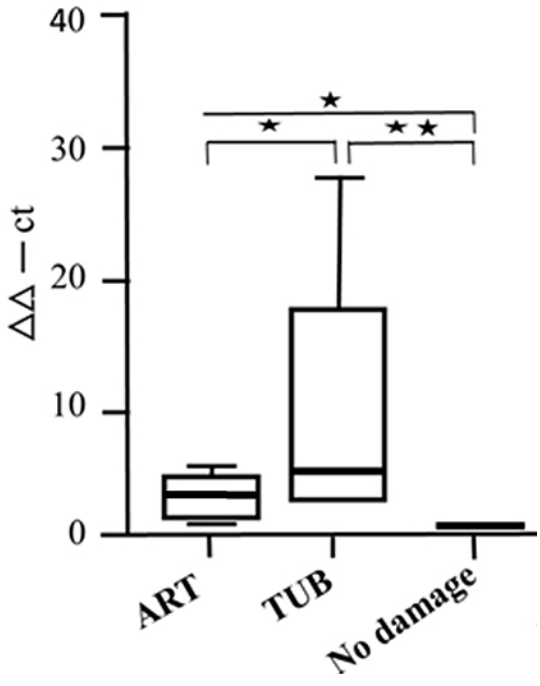

Figure 4B. qRT-PCR analysis of miRNA133a in renal biopsies with CyA damage (arteriolar; tubular); no damage as controls. Values from normal renal tissue of tumor resection specimens served to calculate ddct values $\left({ }^{*} \mathrm{p}<0.05, * * \mathrm{p}<0.01\right)$

Volume 5: 9 -12 
Since CyA is considered a therapeutic option in steroid resistant nephrotic syndrome particularly in African children with focalsegmental sclerosis, and proteinuric renal disease may cause a downregulaion of MRP2 already, the combination may well lead to nephorotoxicity. However, renal dialysis for these children is not readily available, and the reported degree of CyA induced nephrotoxicity in thosechildrenis $10 \%[34$ ] to $11.7 \%$ [35], respectively. Thus, prevention/ amelioration of toxic side effects of $\mathrm{CyA}$ is highly desirable.

Urinary ET-1 upregulation has also been reported after cyclosporine administration and was found to be increased in kidneys after 1 year of cyclosporine treatment [36]. In the animal models of killifish [3] and shark [8], the effect of tubulotoxicity was mediated by binding of ET-1 to the ETBR. In 2015, Loser, et al. proposed a signaling mechanism in humans where ET-1 stimulation via ETBR leads to upregulation of miRNA133a. This miRNA binds to the 3'UTR of the mrp2 gene, preventing its translation and causing a loss of stainable MRP2. As we have shown [25], this mechanism occurs in different forms of glomerulonephritis (minimal change disease, membranous nephropathy), and could be demonstrated in the Adriamycin mouse model of proteinuria. These results led us to investigate the relationship between MRP2 and miRNA133a in nephrotoxicity, using CyA treated biopsies from transplant patients.

In the CyA group with arteriolar damage a marked loss of MRP2 detection was found: a mean value of $34 \%$ of tubules with more than $50 \%$ ofMRP 2 staining and $41 \%$ of those withless than $50 \%$ of detectable staining (Figure 3). At the transcriptional level for mrp2 there was a high response with an average of $60 \%$, while the at the miRNA133a level, only a low level of transcription was identified (Figure 4). Thus, in arteriolar damaged kidneys the downregulation of MRP2 seems to be predominantly caused by ischemia, while only a small increase in miRNA133a is found, indicating a direct downregulation.

This is in marked contrast to tubular damage. While the mean values of immune histologic MRP2 staining are comparable to the ones seen in arteriolar damage (Table 8), the pathomechanism with elevated miRNA133a levels and very low MRP2 transcription points to a predominant downregulation of MRP2 by miRNA133a as the major cause (Figure 4). This reflects a more sincere and troublesome problem in tubular damage than in arteriolar damage, in particular since it cannotbeidentified by immune histologic analysis and morphometry alone. The group with no detectable damage treated with CyA has by light microscopy the highest number of well-preserved tubules; however, even those are damaged when analyzed by immune histologic evaluation (Figure 3). Again, the transcriptional response is minimal on the level of MRP2 as well as on the miRNA133a level (Figure 4), suggesting that this damage seems to be of minor relevanceand is most likely post-ischemic in nature. Altogether, post-ischemic damage due to delayed fixation poses a considerable problem in the evaluation of damages seen by light microscopy, as can be appreciated by comparing

Table 8. Mean +/- standard deviation of groups with MRP2 loss

\begin{tabular}{|c|c|c|c|c|c|c|}
\hline & No damage & arteriolar & tubular & $\begin{array}{c}\text { Arteriolar } \\
+ \text { tubular }\end{array}$ & Controls & F- value \\
\hline $100 \%$ & $\begin{array}{c}3.31 \\
+/-2.36\end{array}$ & $\begin{array}{c}3.45 \\
+/-2.16\end{array}$ & $\begin{array}{c}2.68 \\
+/-2.93\end{array}$ & $\begin{array}{c}3.01 \\
+/-3.16\end{array}$ & $\begin{array}{c}10.63 \\
+/-7.17\end{array}$ & 4.94 \\
\hline$>50 \%$ & $\begin{array}{c}56.64 \\
+/-10.24\end{array}$ & $\begin{array}{c}34.21 \\
+/-12.30\end{array}$ & $\begin{array}{c}39.42 \\
+/-19.19\end{array}$ & $\begin{array}{c}34.21 \\
+/-12.30\end{array}$ & $\begin{array}{c}78.11 \\
+/-10.30\end{array}$ & 9.73 \\
\hline$<50 \%$ & $\begin{array}{c}33.63 \\
+/-11.54\end{array}$ & $\begin{array}{c}40.99 \\
+/-22.61\end{array}$ & $\begin{array}{c}42.19 \\
+/-18.34\end{array}$ & $\begin{array}{c}39.67 \\
+/-25.89\end{array}$ & $\begin{array}{c}12.26 \\
+/-10.21\end{array}$ & 2.84 \\
\hline $0 \%$ & $\begin{array}{c}4.84 \\
+/-2.78\end{array}$ & $\begin{array}{c}10.55 \\
+/-2.69\end{array}$ & $\begin{array}{c}13.27 \\
+/-12.37\end{array}$ & $\begin{array}{c}22.16 \\
+/-10.63\end{array}$ & 0 & 6.40 \\
\hline
\end{tabular}

Figure 5. Graphic depicting the effect of CyA +/- ETBR antagonism. Top panel: under control conditions, there is no detectable tubular damage; MRP2 is expressed at the brush border surface. Bottom panel: CyA leading to ET-1 secretion causing downregulation of the mrp2 gene by inducing miRNA133a via the ETBR receptor. A tubular toxicity with isometric vacuolization can be seen by electron microscopy

the result obtained from the so-called null biopsies vs. normal renal tissue from tumor resection specimens (Figure3, Table 2 and 3). Null biopsies come from kidneys, which seem to be suited for transplant by clinical evaluation. However, due to a prolonged allocation time, resulting in a prolonged cold ischemia-time, there is considerable damage observed on the MRP2 levels by morphometry. Finding low miRNA13a levels, we can show that this damage is an artefact due to poor preservation and not due to in vivo CyA inflicted tubular toxicity. In contrast, normal renal tissue taken from tumor resection specimens and used primarily for frozen sections diagnosis was clearly exposed to less ischemic time and showed a good preservation with expectantly low miRNA133a levels as well. For this reason, we used these cases as reference to calculate the ddct values. Thus, the histologic analysis alone does not provide a reliable measure of ongoing molecular changes leading to the development of renal dysfunction, which seem detectable by measuring miRNA13alevels.

From the aforementioned results and our previous report about the detectability of miRNA133a in the urine of patients [25], downregulated MRP2 transporter could be anticipated by levels of miRNA133a, as assay in the urine. This may help in guiding therapy by better anticipating renal failure, while an adjunctETBRantagonism may allow a better tolerance of CyA therapy, preventing unnecessary renal failure. This has been suggested from in vitro experiments, where the toxicity of CyA on cells from proximal tubules such as LLC-PK1 and MDCK has been blocked by an ETBR but not an ETAR antagonism [37].

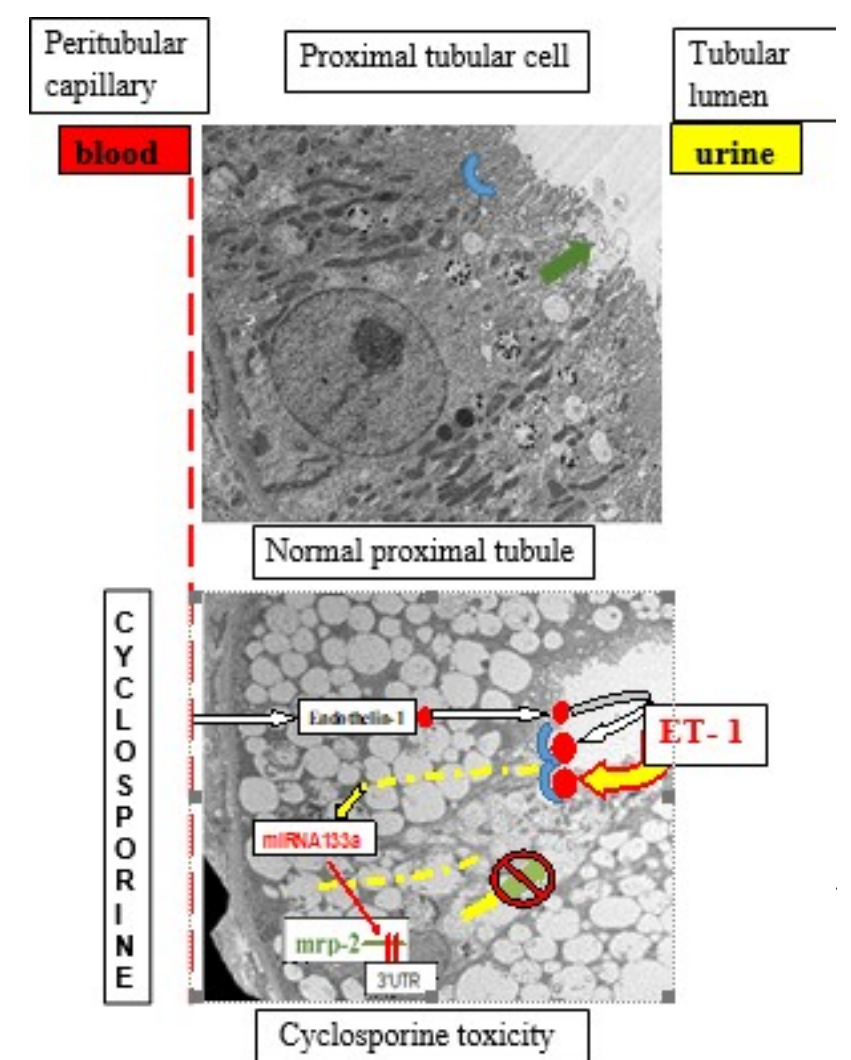


Using an ETBR antagonist may concomitantly help to avoid CyA mediated arteriolopathy, in analogy to Zheng, et al. [38] who have demonstrated that CyA activates ETBR in vascular smooth muscle cells via MAPK and NF-kB. Furthermore, blocking the ETBR prevents microvascular damage of CyA to neocapillaries [39].

\section{Conclusion}

In summary (Figure 5), we know so far that CyA induced tubular damage is associated with increased ET- 1 levels [10-12], transactivating signaling into proximal tubules via increased levels of ETB-receptor [13]. This leads to a detectable loss of the MRP2 expression at the brush border level. This is caused by a PKC mediated [8] upregulation of miRNA 133a binding to the 3' UTR of mrp2 [25] and leads to increased levels of miRNA133a in the urine [25]. Blocking this signaling cascade by an ETBR antagonist will preserve MRP2 expression, while downregulating detectable miRNA133a levels [25]. While this mechanism presents itself as a diagnostic tool to measure MRP2 loss, and may be prevented by an ETBR antagonist, its clinical application has to be investigated in a respective study.

\section{Acknowledgements}

The authors declare no-financial competing interests.

We gratefully acknowledge the help in immune histology by Mrs. Uschi Zenz.

\section{References}

1. Gerstung M, Roth T, Dienes HP, Licht C, Fries JW. (2007) Endothelin-1 induces NFkappaB via two independent pathways in human renal tubular epithelial cells. $\mathrm{Am} \mathrm{J}$ Nephrol 7: 294-300.

2. Ong AC, Jowett TP, Firth JD, Burton S, Karet FE, et al. (1995) An endothelin-1 mediated autocrine growth loop involved in human renal tubular regeneration. Kidney Int 48: 390-401.

3. Masereeuw R, Terlouw SA, van Aubel RA, Russel FG, Miller DS (2000) Endothelin $\mathrm{B}$ receptor-mediated regulation of ATP-driven drug secretion in renal proximal tubule. Mol Pharmacol 57: 59-67.

4. Choi $\mathrm{YH}, \mathrm{YuAM}(2014) \mathrm{ABC}$ transporters in multidrug resistance and pharmacokinetics, and strategies for drug development. Curr Pharm Des 20: 793-807.

5. Kool M, de Haas M, Scheffer GL, Scheper RJ, van Eijk MJ, et al. (1997) Analysis of expression of cMOAT (MRP2), MRP3, MRP4, and MRP5, homologues of the multidrugresistance-associated protein gene (MRP1), in human cancer cell lines. Cancer Res 57: 3537-3547.

6. Terlouw SA, Masereeuw R, Russel FG, Miller (1997) Nephrotoxicants induce endothelin release and signaling in renal proximal tubules: effect on drug efflux. DS Mol Pharmacol 59: 1433-1440.

7. Wen X, Buckley B, McCandlish E, Goedken MJ, Syed S, et al. (1997) Transgenic expression of the human mrp2 transporter reduces cisplatin accumulation and nephrotoxicity in mrp2-null mice. Am J Pathol 184: 1299-1308.

8. Miller DS, Masereeuw R, Karnaky KJ, Jr. (2002) Regulation of mrp2-mediated transport in shark rectal salt gland tubules. Am J Physiol Regul Integr Comp Physiol 282: R774- R781.

9. König J, Nies AT, Cui Y, Leier I, Keppler D (1999) Conjugate export pumps of the multidrug resistance protein (MRP) family: localization, substrate specificity, and MRP2-mediated drug resistance. Biochim Biophys Acta 1461: 377-3794.

10. Rezzani R, Rodella L, Bianchi R (2001) Induction of Endothelin-1 in rat kidney after Cyclosporine A treatment. Acta histochem 103:423-431.

11. Haug C, Grill Chr, Schmid-Kotsas A, Gruenert A, Jehle PM (1998) Endothelin release by rabbit proximal tubule cells: Modulatory effects of cyclosporine A, tacrolimus, HGF and EGF. Kidney Int 54: 1626-1636.

12. Papachristou E, Papadimitropoulos A, Kotsantis P, Goumenos DS, Katsoris PG, et al (2009) Cyclosporine induces endothelin-1 mRNA synthesis and nitric oxide production in human proximal tubular epithelial cell cultures. Ren Fail 31: 372-376.
13. Papachristou E, Papadimitropoulos A, Kotsantis P, Goumenos DS, Katsoris PG, et al. (2010) Interaction of endothelin-1 and nitric oxide pathways in human tubula epithelial cells under the influence of cyclosporine-A CsA stimulates ET-1 and NO pathways in HK-2 cells. Ren Fail 32: 727-732.

14. Solez K, Colvin RB, Racusen LC, Haas M, Sis B, et al. (2008) Banff 07 classification of renal allograft pathology: updates and future directions. Am J Transplant 8: 1-8.

15. von Brandenstein M, Depping R, Schafer E, Dienes HP, Fries JW (2011) Protein kinase $\mathrm{C}$ alpha regulates nuclear pri-microRNA $15 \mathrm{a}$ release as part of endothelin signaling. Biochim Biophys Acta 1813: 1793-1802.

16. von Brandenstein MG, Ngum Abety A, Depping R, Roth T, Koehler M, et al. (2008) A p38-p65 transcription complex induced by endothelin-1 mediates signal transduction in cancer cells. Biochim Biophys Acta 1783: 1613-1622.

17. Jemnitz K, Heredi-Szabo K, Janossy J, Ioja E, Vereczkey L, et al. (2010) ABCC2 Abcc2: a multispecific transporter with dominant excretory functions. Drug Metab Rev 42: $402-436$.

18. Tang F, Horie K, Borchardt RT (2002) Are MDCK cells transfected with the human MRP2 gene a good model of the human intestinal mucosa? Pharm Res 1: 773-779.

19. Morrissey KM, Wen CC, Johns SJ, Zhang L, Huang SM, et al. (2012) The UCSF-FDA TransPortal: a public drug transporter database. Clin Pharmacol Ther 92: 545-546.

20. Stiller C (1984) Update for the Canadian multicenter trial of cyclosporine in renal allografts. The New England Journal of Medicine 310: 1464-1465.

21. Cattaneo D, Perico N, Gaspari F, Remuzzi G (2004) Nephrotoxic aspects of cyclosporine. Transplant Proc 36: 234S-239S

22. Morozumi K, Takeda A, Uchida K, Mihatsch MJ (2004) Cyclosporine nephrotoxityHow does it affect renal allografts function and transplant morphology. Transplant Proc 36: $251-256$.

23. Howard R, Datton PR, Reed AI, Hemming A, van der Werf WS, et al. (2002) The changing causes of graft loss and death after kidney transplantation. Transplantation 73: 1923-1928.

24. Nashan B, Armstrong VW, Budde K, Friche L, Heemann U, et al. (2003) Cyclosporin C2-Monitoring zur Optimierung der Immunsuppression nach Nierentransplantation. Transplantations medizin 15: 15-24.

25. Loeser H, von Brandenstein M, Herschung A, Schlosser M, Buettner R, et al. (2015) ET-1 Induced Downregulation of MRP2 via miRNA 133a - A marker for tubular nephrotoxicity? Am J Nephrol 41: 191-199.

26. Mauiyyedi S, Crespo M, Collins AB, Schneeberger EE, Pascual MA, et al. (2002) Acute humoral rejection in kidney transplantation, II Morphology, immunopathology and pathologic classification. JASN 13: 779-787.

27. Mihatsch MJ, Ryffel B, Hermle M, Brunner FP, Thiel G (1986) Morphology of cyclosporine nephrotoxicity in the rat. Clin Nephrol Suppl 1: S2-S8.

28. Joosten SA, Sijpkens YW, van Kooten C, Paul LC (2005) Chronic renal allograft rejection: pathophysiologic considerations. Kidney Int 68: 1-13.

29. Liptak P, Ivanyi B (2006) Primer: histopathology of calcineurin- inhibitor toxicity in renal allografts. Nature clinical practice Nephrology 2: 398-404.

30. Snanoudj R, Royal V, Elie C, Rabant M, Girardin C, et al. (2011) Specificity of histological markers of long-term CNI nephrotoxity in kidney-transplant recipient under low-dose cyclosporine therapy. American Journal of Transplantation 11: 2635-2646.

31. Cardarelli F, Pascual M, Tolkoff-Rubin N, Delmonico FL, Wong W, et al. (2005) Prevalence and significance of anti-HLA and donor-specific antibodies long-term after renal transplantation. Transpl Int 18: 532-540.

32 El-Sheikh AAK, Greupink R, Wortelboet HM, Van den Heuvel JJMW, Schruer $\mathrm{M}$, et al. (2013) Interaction of immunosuppressive drugs with human organic anion transporter (OAT) 1 and OAT3, and multidrug resistance-associated protein (MRP) 2 and MRP4. Transl Res 162: 399-409.

33. Thoenes W, Fries J (1983) Micromorphology of the nephron in experimental temporary ischemic kidney and in human acute renal failure. Acute renal failure: pathophysiology, its significance for intrarenal surgery and prevention. Muenchen. Zuckschwerdt Verlag 1-23.

34. Choudhry S, Bagga A, Hari P, Sharma S, Kalaivani M, et al. (2009) Efficacy and safety of tacrolimus versus cyclosporine in children with steroid-resistant nephrotic syndrome: a randomized controlled trial. Am J Kid Dis 53: 760-769.

35. Frassinetti C, Da Silva BG Jr, De Sousa BFA, Oliveira CCM, Kubrusly M, et al. (2005) Treatment of steroid-resistant nephrotic syndrome with cyclosporine: study of 17 cases and a literature review. $J$ Nephrol 18: 711-720. 
Fries JWU (2020) Cyclosporine A nephrotoxicity: Downregulation of multidrug resistance associated protein 2 (MRP2) by upregulated miRNA133a

36. Benigni A, Bruzzi I, Mister M, Azzollini N, Gaspari F, et al. (1999) Nature and mediators of renal lesions in kidney transplant patients given cyclosporine for more than one year. Kidney Int 55: 674-685.

37. Zimmerhackl LB, Mesa H, Krämer F, Kölmel C, Wiegele G, et al. (1997) Tubular toxicity of cyclosporine A and the influence of endothelin-1 in renal cell culture models (LLC-PK1 and MDCK). Pediatr Nephrol 11: 778-783.
38. Zheng JP, Cheng Z, Jiang J, Ke Y, Liu Z (2015) Cyclosporin A upregulates ETB receptor in vascular smooth muscle via activation of mitogen-activating protein kinases

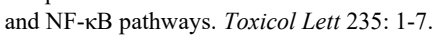

39. Wilasrusmee C, Ondocin P, Bruch D, Shah G, Kittur S, et al. (2003) Amelioration of cyclosporin A effect on microvasculature by endothelin inhibitor. Surgery 134: $384-$ 389.

Copyright: ( 2020 Fries JWU. This is an open-access article distributed under the terms of the Creative Commons Attribution License, which permits unrestricted use, distribution, and reproduction in any medium, provided the original author and source are credited. 